\title{
Formation of methyl formate after cosmic ion irradiation of icy grain mantles
}

\author{
P. Modica and M. E. Palumbo
}

\author{
INAF - Osservatorio Astrofisico di Catania, via Santa Sofia 78, 95123 Catania, Italy \\ e-mail: mepalumbo@oact.inaf.it
}

Received 19 January 2010 / Accepted 25 May 2010

\begin{abstract}
Context. Methyl formate $\left(\mathrm{HCOOCH}_{3}\right)$ is a complex organic molecule detected in hot cores and hot corinos. Gas-phase chemistry fails to reproduce its observed abundance, which usually varies between $10^{-7}$ and $10^{-9}$ with respect to $\mathrm{H}_{2}$.

Aims. Laboratory experiments were performed in order to investigate a solid-state route of methyl formate formation, to obtain an estimate of the amount that can be formed, and to verify whether it can account for the observed abundances.

Methods. Several solid samples $(16 \mathrm{~K})$ of astrophysical interest were analyzed by infrared spectroscopy in the $4400-400 \mathrm{~cm}^{-1}$ range. The infrared spectral characteristics of frozen methyl formate were studied by deriving their band strength values. The effects produced upon warm-up of the samples were analyzed comparing the spectra taken at different temperatures. In order to study the formation and destruction mechanism of methyl formate in the interstellar ices, a binary mixture of methanol $\left(\mathrm{CH}_{3} \mathrm{OH}\right)$ and carbon monoxide (CO) ice and a sample of pure methanol were irradiated at $16 \mathrm{~K}$ with $200 \mathrm{keV}$ protons. Methyl formate was identified through its fundamental mode $\left(\mathrm{CH}_{3}\right.$ rocking) at about $1160 \mathrm{~cm}^{-1}$.

Results. We present the mid-infrared methyl formate ice spectrum showing both the amorphous $(16 \mathrm{~K})$ and the crystalline (110 K) structure. We report novel measurements of the band strength values of the six main methyl formate bands. We prove the formation and the destruction of methyl formate after irradiation of $\mathrm{CH}_{3} \mathrm{OH}$ and a $\mathrm{CO}: \mathrm{CH}_{3} \mathrm{OH}$ mixture. Extrapolating our results to the interstellar medium conditions we found that the production timescale of methyl formate agrees well with the evolutionary time of molecular clouds. The comparison with the observational data indicates that the amount of methyl formate formed after irradiation can account for the observed abundances.

Conclusions. The present results allow us to suggest that gas phase methyl formate observed in dense molecular clouds is formed in the solid state after cosmic ion irradiation of icy grain mantles containing $\mathrm{CO}$ and $\mathrm{CH}_{3} \mathrm{OH}$ and released to the gas phase after desorption of icy mantles.
\end{abstract}

Key words. astrochemistry - molecular data - ISM: abundances - ISM: clouds - methods: laboratory

\section{Introduction}

Dust grains inside dense molecular clouds are covered by icy mantles. These are volatile structures consisting of simple molecules and atoms such as carbon monoxide, oxygen, and nitrogen. Other molecules can be produced on the grain surface by successive hydrogenation of condensed species and/or interaction with low-energy cosmic rays and UV photons (e.g. Tielens \& Hagen 1982; Grim \& Greenberg 1987; Palumbo \& Strazzulla 1993). The radiation field modifies the pristine ices ionizing the molecules and producing radicals that after recombination can form new species. As a consequence icy mantles are composed of water, carbon monoxide, carbon dioxide, traces of formaldehyde, methanol, ammonia, and possibly even more complex molecules (e.g. Boogert et al. 2008; Gerakines et al. 1999). When a young stellar object begins to form, the dust reaches the appropriate sublimation temperature of the ices, then the icy mantles sublime releasing their components into the gas phase. They may condense onto the grain surface again during the proto-planetary disk phase. Perhaps they are incorporated into the planetesimal forming the building blocks of planets, or into comets and asteroids.

In the astrophysical context, organic molecules with more than four atoms are usually considered complex and are called complex organic molecules (COMs). Some COMs are interesting to biology because they are linked to the origin of life. They are known to exist in hot cores of star-forming regions (e.g. Ikeda et al. 2001), which are characterized by relatively high temperature $(T \geq 100 \mathrm{~K})$ and density $\left(n \geq 10^{6} \mathrm{~cm}^{-3}\right)$. In these objects icy mantles have sublimated. For over two decades, COMs have been detected only in massive hot cores, while recently they have also been observed in three hot corinos, lowmass star-forming regions (Cazaux et al. 2003; Kuan et al. 2004; Bottinelli et al. 2004a,b). Because hot corinos have sizes of a few tens of AU, the size of the solar nebula, it is particularly relevant to study the COMs formation and destruction mechanism because of the link to the formation of the Solar System. Such complex molecules would provide early proto-planetary nebulae with a rich organic inventory similarly to that expected to have occurred in our presolar nebula. Clues that connect the interstellar chemistry to the Solar System can be found in the cometary detection of COMs (Sandford et al. 2006) because comets are believed to contain the most pristine material remaining from the presolar nebula. They may have carried prebiotic organic chemistry from the interstellar clouds to the early Earth.

Of the COMs detected so far, special attention has been paid to the formation of the $\mathrm{C}_{2} \mathrm{H}_{4} \mathrm{O}_{2}$ isomers - methyl formate $\left(\mathrm{HCOOCH}_{3}\right)$, acetic acid $\left(\mathrm{CH}_{3} \mathrm{COOH}\right)$, and glycolaldehyde $\left(\mathrm{HOCH}_{2} \mathrm{CHO}\right)-$ molecules that have the same chemical formula but differ in the way atoms are connected. These molecules 
may provide important clues to the formation chemistry of large biomolecules. From recent observations in Sgr B2 N(NLH), it is estimated that the relative abundances of the three molecules are 1864:103:1 (methyl formate: acetic acid: glycolaldehyde) and the fractional abundances relative to $\mathrm{H}_{2}$ are $3.7 \times 10^{-8}, 2.0 \times$ $10^{-9}, 2.0 \times 10^{-11}$ for methyl formate, acetic acid, and glycolaldehyde respectively (Bennett \& Kaiser 2007).

This paper focuses on methyl formate $\left(\mathrm{HCOOCH}_{3}\right)$, the most abundant of $\mathrm{C}_{2} \mathrm{H}_{4} \mathrm{O}_{2}$ isomers in hot cores. Methyl formate may provide a connection to acetic acid $\left(\mathrm{CH}_{3} \mathrm{COOH}\right)$ and even to glycine $\left(\mathrm{NH}_{2} \mathrm{CH}_{2} \mathrm{COOH}\right)$, the simplest biologically important amino acid. The first detection of interstellar methyl formate was made by Brown et al. (1975) toward the star-forming region Sgr B2. After it has been detected in several hot cores, in three hot corinos (Bottinelli et al. 2007), and in comets (Bockelée-Morvan et al. 2000; Despois et al. 2005; Remijan et al. 2006). All these detections suggest that methyl formate may be widely distributed in the Galaxy.

One of the open questions about methyl formate is to explain its abundance in the interstellar medium. Although it is generally accepted that methyl formate can be produced from methanol formed in the icy grain mantles, models based only on gas-phase reactions are unable to account for the observed abundances. Until a few years ago it was thought that methyl formate could be formed in the gas phase after the sublimation of icy mantles containing $\mathrm{H}_{2} \mathrm{CO}$ and $\mathrm{CH}_{3} \mathrm{OH}$. Horn and colleagues studied the specific sequence of reactions that was supposed to lead to the synthesis of methyl formate (Horn et al. 2004). The results of their theoretical and experimental gas-phase study have conclusively shown that the processes in the gas phase are unable to produce sufficient amounts of methyl formate. This evidence has profoundly changed the standard production scenario suggesting that methyl formate should be produced mainly by reactions in ices rather than in gas phase. Nowadays new routes of formation and destruction have been proposed in literature, pointing to a much more important role for grain surface reactions and energetic processing of icy mantles than previously believed. Mixtures of methanol and carbon monoxide ices were irradiated at $10 \mathrm{~K}$ with energetic electrons (Bennett \& Kaiser 2007), establishing the formation of glycolaldehyde and methyl formate. Furthermore methyl formate has been observed after $\mathrm{UV}$ photolysis of pure $\mathrm{CH}_{3} \mathrm{OH}$ and $\mathrm{CO}: \mathrm{CH}_{3} \mathrm{OH}$ ice mixtures (Gerakines et al. 1996; Öberg et al. 2009).

Methyl formate has not yet been observed in the solid state as a component of icy grain mantles because its strongest bands overlap with those from other present and more abundant molecules. Both $\mathrm{CO}$ and $\mathrm{CH}_{3} \mathrm{OH}$ are found to be abundant within the grain mantles. Recently, it was experimentally shown that $\mathrm{CH}_{3} \mathrm{OH}$ can be produced efficiently by successive hydrogenation of CO (Watanabe et al. 2007; Fuchs et al. 2009). As a consequence, these two components are supposed to reside well mixed in the icy mantles.

In this work we will investigate the formation and destruction of methyl formate in the solid state after cosmic ion irradiation of icy grain mantles containing $\mathrm{CO}$ and $\mathrm{CH}_{3} \mathrm{OH}$. Our purpose is to study in the laboratory the formation mechanism suggested, to quantitatively evaluate the amount of methyl formate that can be formed, and to assess whether it is able to produce methyl formate in such quantities to justify the observed abundances in the interstellar medium. In this regard we conducted experiments that simulate the chemical-physical effects induced on icy mantles after cosmic ion irradiation. In order to study the formation of methyl formate within interstellar ices, we chose to investigate the effects of $200 \mathrm{keV}$ protons on a binary ice mixture of carbon monoxide and methanol $\left(\mathrm{CO}: \mathrm{CH}_{3} \mathrm{OH}=1.6: 1\right)$ and a sample of pure methanol at $16 \mathrm{~K}$. These effects were studied by infrared spectroscopy. We have performed new laboratory experiments, which enabled us to obtain an estimate of the amount of methyl formate formed after irradiation.

\section{Experimental procedure}

\subsection{Experimental set-up}

The present experiments were performed in the Laboratory for Experimental Astrophysics at INAF-Osservatorio Astrofisico di Catania (Italy). The experimental apparatus used to obtain infrared transmission spectra is composed of a stainless steel high-vacuum chamber operating at a pressure $P<10^{-7} \mathrm{mbar}$ interfaced with a FTIR spectrometer (4400-400 $\mathrm{cm}^{-1}=$ 2.27-25 $\mu \mathrm{m}$ ) through IR-transparent windows. The gas or gas mixture to be investigated is injected into the chamber through a needle valve and subsequently frozen onto a chosen substrate $(\mathrm{Si}$ or $\mathrm{KBr})$ that is in thermal contact with a cold finger (10-300 K).

After deposition the samples were bombarded by $200 \mathrm{keV}$ $\mathrm{H}^{+}$ions. The ions are obtained from an ion implanter interfaced with the vacuum chamber. The beam used produces current densities in the range from $10^{-1}$ to a few $\mu \mathrm{A} \mathrm{cm}^{-2}$ in order to avoid macroscopic heating of the target. The ion beam and the infrared beam are mutually perpendicular while they form an angle of 45 degrees with the substrate plane. In this way, spectra can be taken at any time, before, during, and after irradiation, without tilting the sample. The energy released to the sample by impinging ions (dose) is given in $\mathrm{eV} / 16 \mathrm{u}$, where $\mathrm{u}$ is the unified atomic mass unit defined as $1 / 12$ of the mass of an isolated atom of carbon-12. As discussed by Strazzulla \& Johnson (1991), the dose given in units of eV per small molecule $(16 \mathrm{u})$ is a convenient way to characterize chemical changes and compare the results obtained irradiating different samples.

For each sample, after each step of irradiation, two spectra are taken, one with the electric vector parallel (P polarized) and one perpendicular ( $\mathrm{S}$ polarized) to the plane of incidence, where the polarization of the infrared radiation is selected by rotating a polarizer placed in the path of the infrared beam in front of the detector. All spectra in this work are ratioed to the corresponding spectrum of the background acquired before deposition and were taken at a resolution of $1 \mathrm{~cm}^{-1}$. Each spectrum is plotted on an optical depth scale using the relation $I=I_{0} \cdot \mathrm{e}^{-\tau}$ (Beer-Lambert law), where $\tau=\alpha \cdot x$ ( $\alpha=$ absorption coefficient; $x=$ path length through the material).

A detailed description of the experimental apparatus used can be found elsewhere (Strazzulla et al. 2001; Palumbo et al. 2004).

\subsection{Thickness measurement}

In this experimental set-up it is possible to measure the thickness of the frozen samples. Here we followed the same procedure described in Fulvio et al. (2009). During deposition a He-Ne laser beam $(\lambda=543 \mathrm{~nm})$ is directed towards the sample and reflected by the vacuum-sample and the sample-substrate interfaces (Fig. 1). After the reflection the laser beam is detected by an external silicon-diode detector. Between the reflected components of the laser beam there is a difference of optical path, which grows with increasing thickness. Because of this, interference is produced. By looking in real time at the interference 


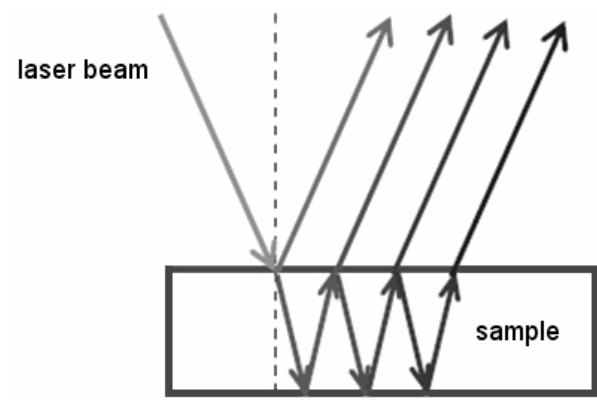

Fig. 1. Scheme of the multiple reflections of the laser beam by the vacuum-sample and the sample-substrate interfaces.

curve (intensity versus time) it is possible to monitor the accretion of the sample during deposition. We used two different substrates for deposition: $\mathrm{Si}$ and $\mathrm{KBr}$.

To measure the thickness of the sample it is first of all necessary to determine its refractive index $n_{\mathrm{f}}$. We can obtain this value from the interference curve with a numerical method (Baratta \& Palumbo 1998). Because the amplitude of the experimental interference curve depends on the refractive index $n_{\mathrm{f}}$ and on other known quantities (the refractive index $n_{\mathrm{s}}$ of the substrate, the incidence angle $\theta_{\mathrm{i}}$, and the polarization of the laser light), $n_{\mathrm{f}}$ can be derived measuring the intensity ratio between maxima and minima in the experimental interference curve. For $\mathrm{HCOOCH}_{3}$ deposited on $\mathrm{Si}$ at $16 \mathrm{~K}$, the value found is $n_{\mathrm{f}}=1.30$.

Once $n_{\mathrm{f}}$ was derived, we could also obtain the theoretical interference curve (reflectance) versus thickness. For nonabsorbing materials this curve is a periodic function. We could measure the thickness of the deposited sample by comparing the theoretical interference curve with the experimental one, normalized from 0 to 1 . For each chosen point on the experimental interference curve, we normalized the intensity value of radiation from 0 to 1 . Then in the theoretical curve we identified the point at which this ordinate corresponds. The abscissa of the point found is the value of the thickness. We considered five thickness values.

The absolute accuracy of the thickness measured in this way is about $5 \%$. It is limited mainly by the uncertainties in the knowledge of the optical constants of the substrate at low temperature and by the error in measuring the incidence angle of the laser beam. The thickness is corrected by a factor of

$$
\frac{1}{\cos \theta_{\mathrm{r}}}=\frac{1}{\sqrt{1-\frac{\sin ^{2} \theta_{\mathrm{i}}}{n_{\mathrm{f}}^{2}}}},
$$

where $\theta_{\mathrm{r}}$ is the refractive angle. This correction takes into account the increased path length of the IR beam at an incidence angle $\theta_{\mathrm{i}}=45 \mathrm{deg}$.

\section{Results}

\section{1. $\mathrm{HCOOCH}_{3}$}

Methyl formate $\left(\mathrm{HCOOCH}_{3}\right)$ is the methyl ester of formic acid (HCOOH). Its mid-infrared spectrum at $16 \mathrm{~K}$ (see Fig. 2) shows six main absorption bands due to molecular vibrations. The strong band at $1720 \mathrm{~cm}^{-1}$ is due to the $\mathrm{C}=\mathrm{O}$ stretching vibration ( $v_{4}$ mode). The two strong bands at 1210 and $1164 \mathrm{~cm}^{-1}$ are due to the $\mathrm{C}-\mathrm{O}$ stretching vibration ( $v_{8}$ mode) and the $\mathrm{CH}_{3}$ rocking vibration ( $v_{9}$ mode) respectively. The double peak at 1435 and $1450 \mathrm{~cm}^{-1}$ is due to the $\mathrm{CH}_{3}$ deformation ( $v_{14}, v_{6}$ modes).

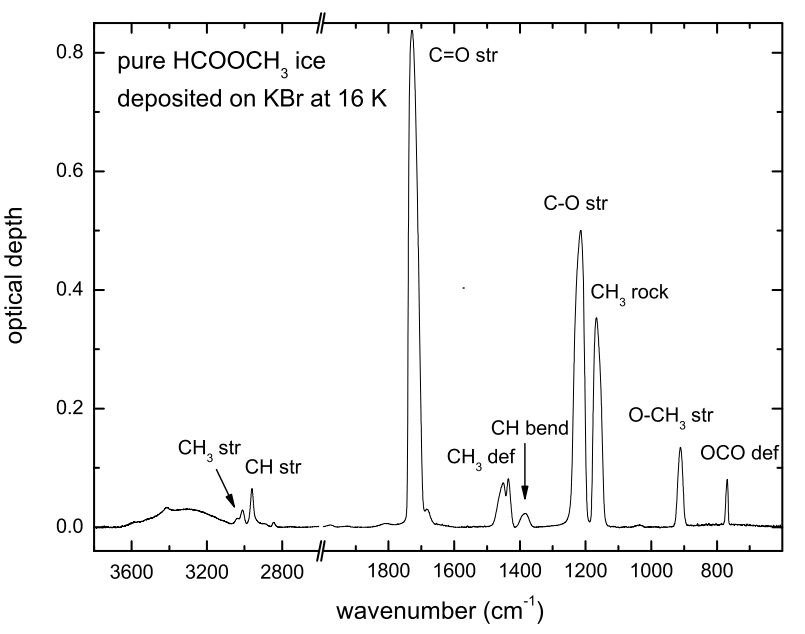

Fig. 2. IR spectrum of a pure $\mathrm{HCOOCH}_{3}$ ice deposited at $16 \mathrm{~K}$ from 3800 to $600 \mathrm{~cm}^{-1}(2.6-16.7 \mu \mathrm{m})$.

Table 1. Band positions of solid methyl formate deposited at $16 \mathrm{~K}$ and their assignments.

\begin{tabular}{|c|c|c|c|}
\hline \multicolumn{2}{|c|}{ Band position } & Assignment & Characterization \\
\hline 3038 & 3.29 & $v_{1}$ & $\mathrm{CH}_{3} \mathrm{str}$ \\
\hline 3010 & 3.32 & $v_{2}, v_{13}$ & $\mathrm{CH}_{3}$ str \\
\hline 2960 & 3.38 & $v_{3}$ & $\mathrm{CH}$ str \\
\hline 1720 & 5.81 & $v_{4}$ & $\mathrm{C}=\mathrm{O}$ str \\
\hline 1450 & 6.90 & $v_{6}$ & $\mathrm{CH}_{3}$ def \\
\hline 1435 & 6.97 & $v_{14}$ & $\mathrm{CH}_{3}$ def \\
\hline 1383 & 7.23 & $v_{7}$ & $\mathrm{CH}$ bend \\
\hline 1210 & 8.26 & $v_{8}$ & $\mathrm{C}-\mathrm{O}$ str \\
\hline 1164 & 8.59 & $\nu_{9}$ & $\mathrm{CH}_{3}$ rock \\
\hline 910 & 10.99 & $v_{10}$ & $\mathrm{O}-\mathrm{CH}_{3}$ str \\
\hline 768 & 13.02 & $v_{11}$ & OCO def \\
\hline
\end{tabular}

The two sharp bands at $910 \mathrm{~cm}^{-1}$ and $768 \mathrm{~cm}^{-1}$ are due to the $\mathrm{O}-\mathrm{CH}_{3}\left(v_{10}\right.$ mode) and the OCO deformation ( $v_{11}$ mode) respectively. Table 1 reports the main methyl formate features.

\subsection{Band strengths}

From the derived $n_{\mathrm{f}}$ value, we can also estimate the sample density with the Lorentz-Lorenz relation

$L \rho=\frac{n_{\mathrm{f}}^{2}-1}{n_{\mathrm{f}}^{2}+2}$.

For a given species the Lorentz-Lorenz coefficient $L$ is nearly constant for a fixed wavelength regardless of the material phase and temperature. Furthermore, although $L$ is a function of wavelength, we can assume to a first approximation that it does not vary between $543 \mathrm{~nm}$ and $590 \mathrm{~nm}$ for a material transparent in the visible. With the refractive index and the density values for $\mathrm{HCOOCH}_{3}$ at $590 \mathrm{~nm}$ and room temperature, available from commercial catalogs, we obtain $L=0.217 \mathrm{~cm}^{3} \mathrm{~g}^{-1}$. By substituting this $L$ value in Eq. (2) and the value of the refractive index measured, we obtain for our experimental deposition conditions the density $\rho=0.87 \mathrm{~g} \mathrm{~cm}^{-3}$ for frozen $\mathrm{HCOOCH}_{3}$ at $16 \mathrm{~K}$.

With the values of thickness $d(\mathrm{~cm})$ and density $\rho$ $\left(\mathrm{g} \mathrm{cm}^{-3}\right)$ calculated above, we can derive the column density $N$ 

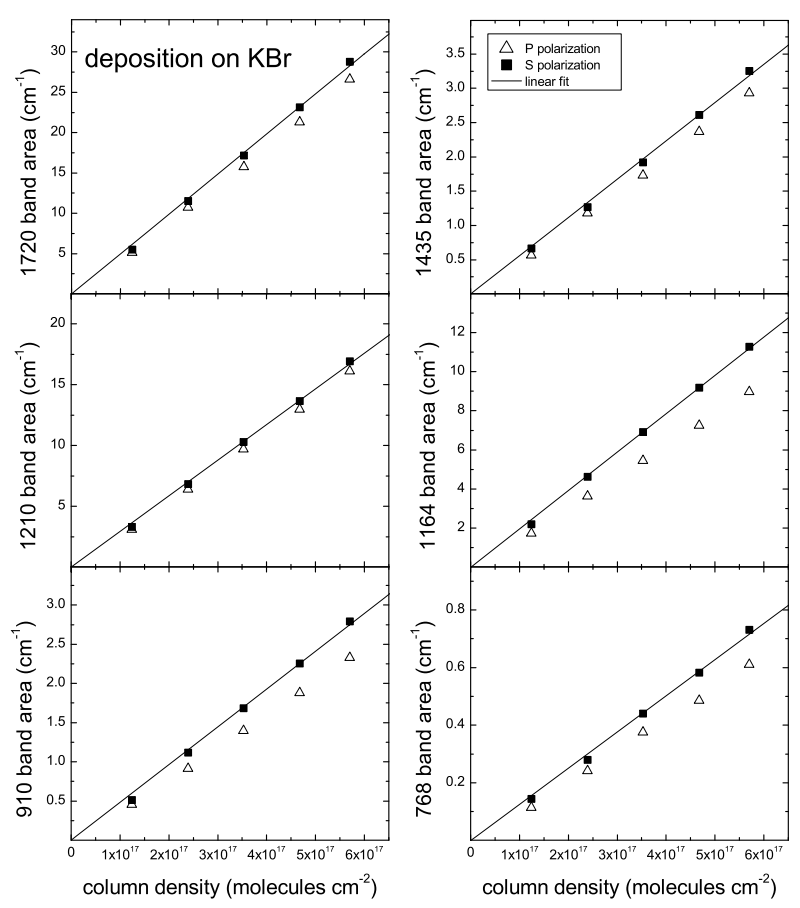

Fig. 3. Individual measures of the band area versus the column density for the $\mathrm{HCOOCH}_{3}$ main bands from spectra taken in $\mathrm{P}$ and in S polarization. Superimposed is the line through the origin that best fits the points in $\mathrm{S}$ polarization.

(molecules $\mathrm{cm}^{-2}$ ) for a species of molecular weight $\mu$ (g) with the relation

$N=\frac{\mathrm{d} \rho}{\mu}$.

The integrated intensity (area) measured of each selected band (in optical depth $\tau(v)$ scale) for a not-saturated band is proportional to the column density, and the following relation is valid:

$$
\int \tau(v) \mathrm{d} v=A \times N
$$

Measuring the integrated intensity of each selected band from the infrared spectra for different thickness values, we get the integrated band strength $A\left(\mathrm{~cm} \mathrm{molecule}{ }^{-1}\right)$ value:

$A=\frac{\int \tau(v) \mathrm{d} v}{N}$.

To derive the band strength values for the main infrared features of frozen $\mathrm{HCOOCH}_{3}$ at $16 \mathrm{~K}$ we plotted each band area against the column density (Figs. 3 and 4). Calculating the best fit of data, the angular coefficients of the straight lines obtained represent the band strength for each selected feature for the two different substrates used for deposition. The band strength values are reported in Table 2. For the double peak at 1435 and $1450 \mathrm{~cm}^{-1}$ we have estimated the $A$ value considering it as a single feature peaked at $1435 \mathrm{~cm}^{-1}$. We note differences due to the substrate in the obtained $A$ value between $6-25 \%$. These differences can be explained by the limits of applicability of the Beer-Lambert law.

\subsection{Warm-up effects}

Because of its high gas phase abundance, the sublimation properties of $\mathrm{HCOOCH}_{3}$ are important.
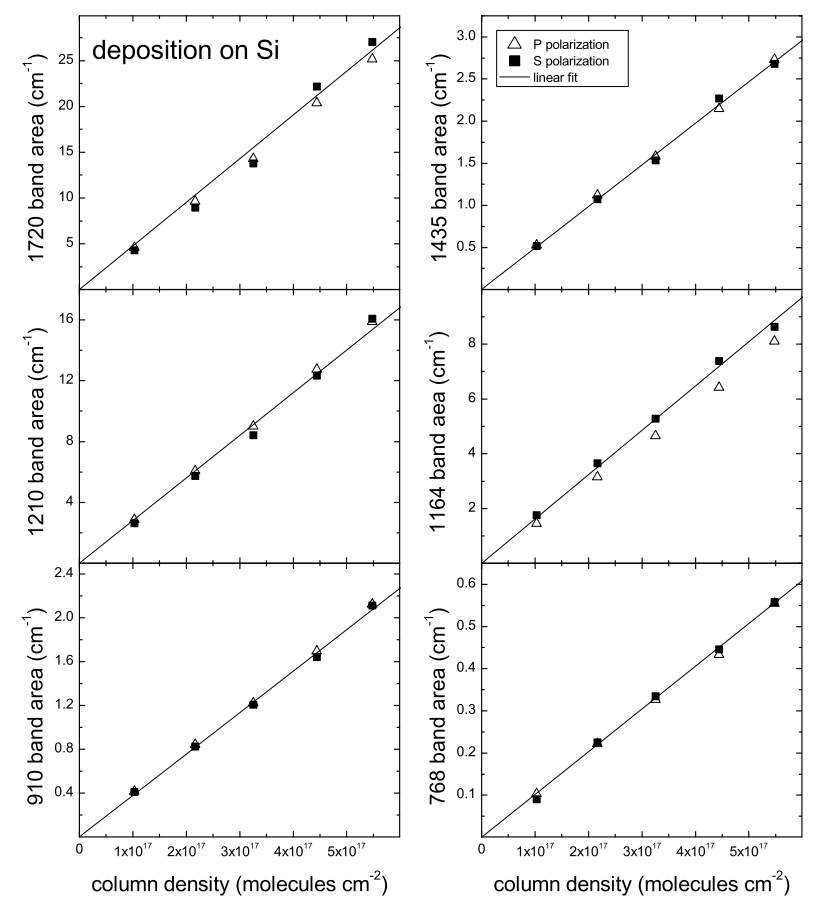

Fig. 4. Individual measures of the band area versus the column density for the $\mathrm{HCOOCH}_{3}$ main bands from spectra taken in $\mathrm{P}$ and in $\mathrm{S}$ polarization. Superimposed is the line through the origin that best fits the points in $\mathrm{S}$ polarization.

Table 2. Band strength values $(A)$ for the most intense features of frozen methyl formate deposited at $16 \mathrm{~K}$ on two different substrates ( $\mathrm{Si}$ and $\mathrm{KBr}$ ).

\begin{tabular}{ccc}
\hline \hline $\begin{array}{c}\text { Band position }\left(\mathrm{cm}^{-1}\right) \\
\text { Substrate }\end{array}$ & \multicolumn{2}{c}{$\left.A(\mathrm{~cm} \mathrm{molecule})^{-1}\right)$} \\
$\mathrm{Si}$ & $\mathrm{KBr}$ \\
\hline 1720 & $4.77 \times 10^{-17}$ & $4.96 \times 10^{-17}$ \\
1435 & $4.94 \times 10^{-18}$ & $5.58 \times 10^{-18}$ \\
1164 & $1.62 \times 10^{-17}$ & $1.96 \times 10^{-17}$ \\
1210 & $2.80 \times 10^{-17}$ & $2.93 \times 10^{-17}$ \\
910 & $3.79 \times 10^{-18}$ & $4.82 \times 10^{-18}$ \\
768 & $1.01 \times 10^{-18}$ & $1.25 \times 10^{-18}$ \\
\hline
\end{tabular}

Methyl formate deposited at $16 \mathrm{~K}$ presents an amorphous structure. The sample was warmed-up and spectra were acquired at $30,50,70,90,110$, and $155 \mathrm{~K}$ (in $\mathrm{P}$ and in $\mathrm{S}$ polarization). In Fig. 5 we compare two spectra taken before $(16 \mathrm{~K})$ and after $(110 \mathrm{~K})$ the warm-up. The individual panels show the profile of the most intense bands. The deep changes in the bottom panels are caused by the crystallization of the sample. It occurs within the temperature range between 90 and $100 \mathrm{~K}$. At $130 \mathrm{~K}$ the sample sublimes.

\section{4. $\mathrm{CH}_{3} \mathrm{OH}: \mathrm{HCOOCH}_{3}$}

A $\mathrm{CH}_{3} \mathrm{OH}: \mathrm{HCOOCH}_{3}=10: 1$ ice mixture was deposited on $\mathrm{KBr}$ at $16 \mathrm{~K}$. The profile of methyl formate bands in mixture with methanol is slightly different from that of the pure sample, in particular the width of the bands decreases. Figure 6 shows the spectral region from 1170 to $1000 \mathrm{~cm}^{-1}$ where we can make a comparison between the $1164 \mathrm{~cm}^{-1}$ band, normalized to the maximum value, in the spectrum of the $\mathrm{CH}_{3} \mathrm{OH}: \mathrm{HCOOCH}_{3}$ ice mixture and in the spectrum of the pure $\mathrm{HCOOCH}_{3}$ ice. The full width at half maximum (FWHM) in the pure sample is $27 \mathrm{~cm}^{-1}$, 
P. Modica and M. E. Palumbo: Formation of methyl formate
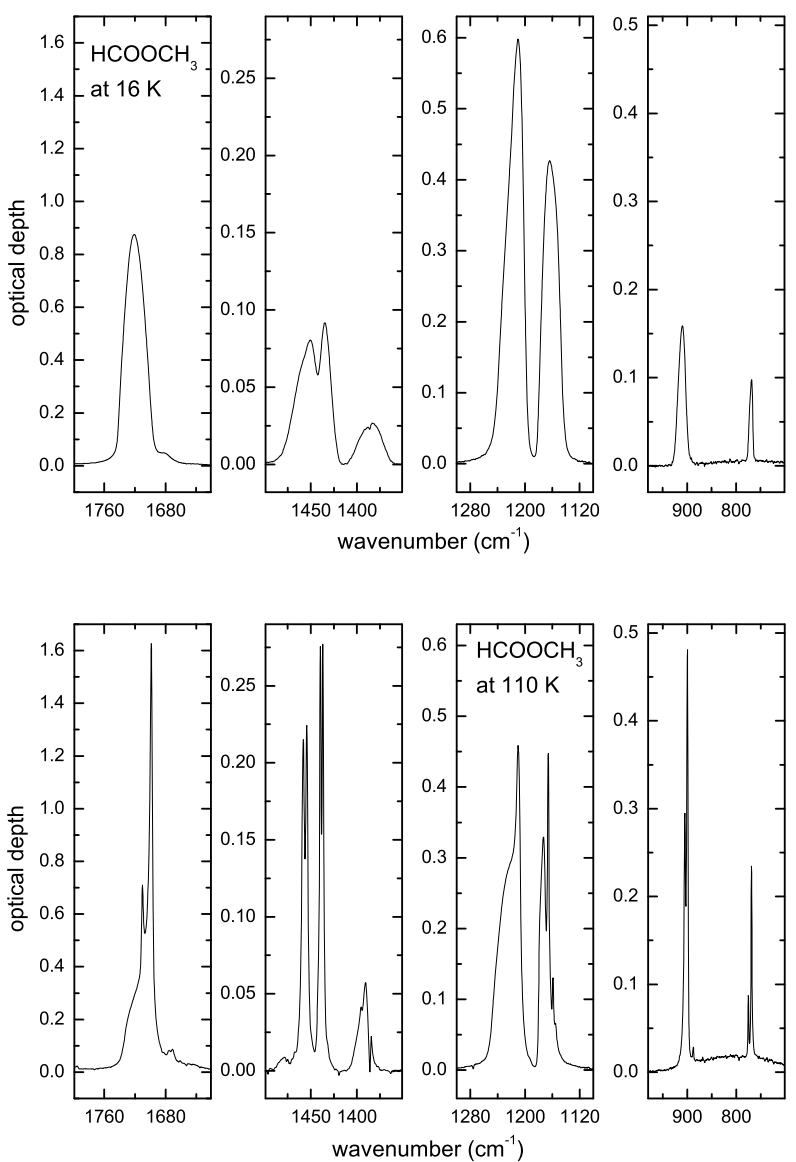

Fig. 5. Profiles of the most intense bands (in $\mathrm{S}$ polarization) in amorphous $\mathrm{HCOOCH}_{3}$ (top panels) and in crystalline $\mathrm{HCOOCH}_{3}$ (bottom panels). The $y$-scale in the panels is different for clarity.

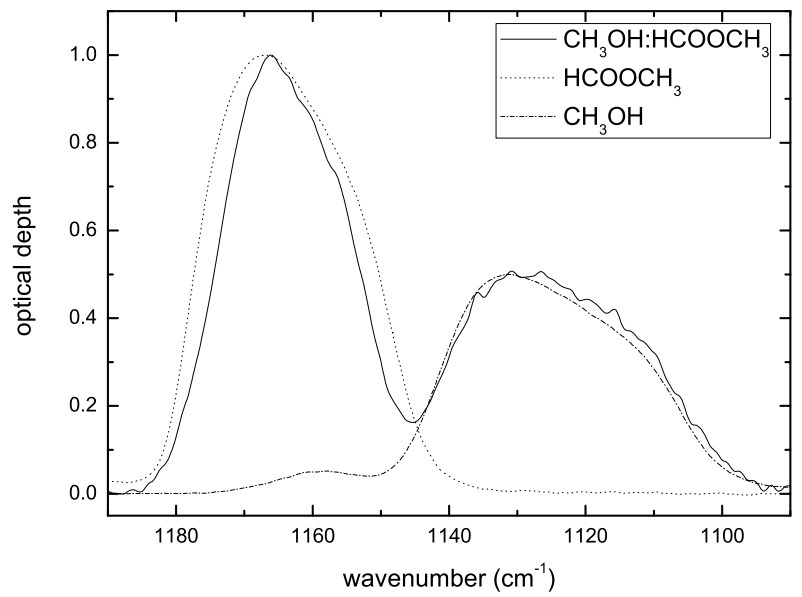

Fig. 6. Comparison between the profile of the band at $1164 \mathrm{~cm}^{-1}$ in pure $\mathrm{HCOOCH}_{3}$ (dotted line) and in a $\mathrm{CH}_{3} \mathrm{OH}: \mathrm{HCOOCH}_{3}=10: 1$ mixture (solid line) at $T=16 \mathrm{~K}$. The spectrum of $\mathrm{CH}_{3} \mathrm{OH}$ (dashed dotted line) is shown for completeness. The optical depth is expressed in arbitrary units.

while in the mixture it is $21 \mathrm{~cm}^{-1}$. For completeness the spectrum of methanol is also shown.

After deposition the ice mixture was warmed-up and spectra were taken at $80,100,120$, and $140 \mathrm{~K}$. In this experiment we found that methyl formate in a mixture with methanol sublimes between 120 and $140 \mathrm{~K}$. This temperature is similar to that of the pure species.

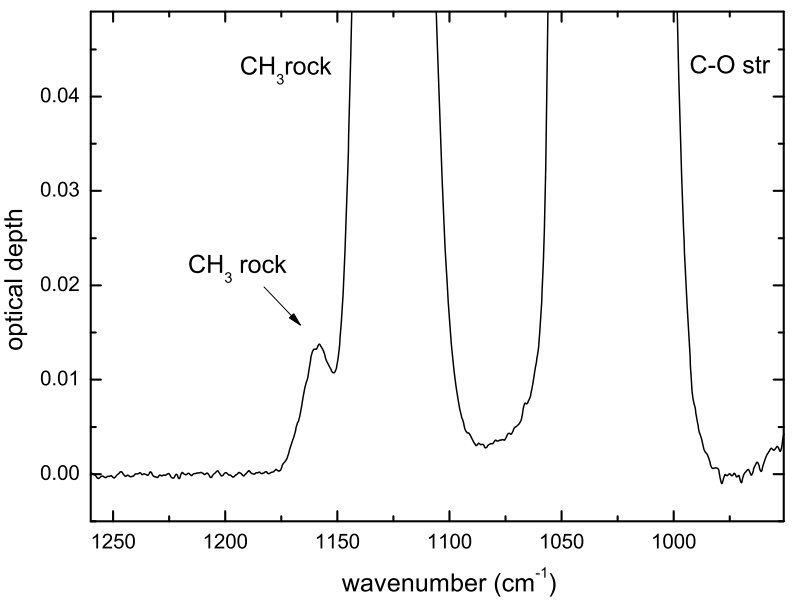

Fig. 7. Enlargement of the methanol spectrum in the $1250-950 \mathrm{~cm}^{-1}$ (8.0-10.5 $\mu \mathrm{m})$ spectral region.

\subsection{Ion irradiation effects}

We irradiated pure $\mathrm{CH}_{3} \mathrm{OH}$ and a $\mathrm{CO}: \mathrm{CH}_{3} \mathrm{OH}$ mixture at $16 \mathrm{~K}$ with $200 \mathrm{keV} \mathrm{H}^{+}$ions.

The mid-IR spectrum of solid methanol (Sandford \& Allamandola 1993; Palumbo et al. 1999; Bennett et al. 2007) presents a wide and intense band centered at $3269 \mathrm{~cm}^{-1}$ due to the $\mathrm{OH}$ stretching ( $v_{1}$ mode), two less intense bands due to the $\mathrm{CH}_{3}$ stretching mode at $2959 \mathrm{~cm}^{-1}\left(v_{2}, v_{9}\right.$ modes $)$ and $2830 \mathrm{~cm}^{-1}$ ( $v_{3}$ mode). In the region between 2600 and $2000 \mathrm{~cm}^{-1}$ there are weak bands due to combination modes and a band at $2049 \mathrm{~cm}^{-1}$ due to overtones. In the last portion of the spectrum there is a band at $1452 \mathrm{~cm}^{-1}$ due to the $\mathrm{CH}_{3}$ deformation ( $v_{4}, v_{5}, v_{10}$ modes), which presents a small shoulder at $1424 \mathrm{~cm}^{-1}$ due to the $\mathrm{OH}$ bending ( $v_{6}$ mode). There is a weak band at $1129 \mathrm{~cm}^{-1}$ due to the $\mathrm{CH}_{3}$ rocking $\left(v_{7}, v_{11}\right.$ modes $)$ and an intense band at $1033 \mathrm{~cm}^{-1}$ due to the $\mathrm{CO}$ stretching ( $v_{8}$ mode). Figure 7 is an enlargement of the $1250-950 \mathrm{~cm}^{-1}$ spectral region, where a weak band due to the $\mathrm{CH}_{3}$ rocking vibration at about $1160 \mathrm{~cm}^{-1}$ is evident.

We compared the IR spectrum of pure methanol frozen at $16 \mathrm{~K}$ with that obtained after irradiation with $200 \mathrm{keV} \mathrm{H}^{+}$ions at a dose of $32.4 \mathrm{eV} / 16 \mathrm{u}$. Because of ion irradiation, methanol molecules are broken and other species are formed as a consequence of recombination of produced radicals and molecular fragments. New bands appear in the spectrum taken after irradiation. The spectral region of interest was divided into three parts for clarity (Fig. 8). In panel (a) a band due to $\mathrm{CH}_{4}$ appears at $3010 \mathrm{~cm}^{-1}$ (Palumbo et al. 1999). In panel (b) $\mathrm{CO}_{2}$ bands appear at $2344 \mathrm{~cm}^{-1}\left({ }^{12} \mathrm{CO}_{2}\right)$ and $2278 \mathrm{~cm}^{-1}\left({ }^{13} \mathrm{CO}_{2}\right)$, while the $\mathrm{CO}$ band appears at $2136 \mathrm{~cm}^{-1}$. In panel (c) we can observe the formation of $\mathrm{H}_{2} \mathrm{CO}$ at $1720 \mathrm{~cm}^{-1}$ (Hudson \& Moore 2000; Bennett \& Kaiser 2007), $\mathrm{CH}_{4}$ at $1304 \mathrm{~cm}^{-1}$, and $\mathrm{C}_{2} \mathrm{H}_{4}(\mathrm{OH})_{2}$ (ethylene glycol) at $1090 \mathrm{~cm}^{-1}$ (Hudson \& Moore 2000). Moreover we can see a weak band near $1160 \mathrm{~cm}^{-1}$ that we attribute to $\mathrm{HCOOCH}_{3}$.

A CO: $\mathrm{CH}_{3} \mathrm{OH}=1.6: 1$ ice mixture was deposited at $16 \mathrm{~K}$. At the end of deposition the thickness was $d=1.65 \mu \mathrm{m}$. The sample was irradiated with $200 \mathrm{keV} \mathrm{H}^{+}$ions and spectra were taken at increasing dose. Also here, new bands appear in the spectra taken after irradiation, which are listed in Table 3. The spectral region of interest was divided into four parts for clarity (Fig. 9). We compared the IR spectrum of the mixture ice at $16 \mathrm{~K}$ with that obtained after irradiation at $18.7 \mathrm{eV} / 16 \mathrm{u}$. In panel (a) we 

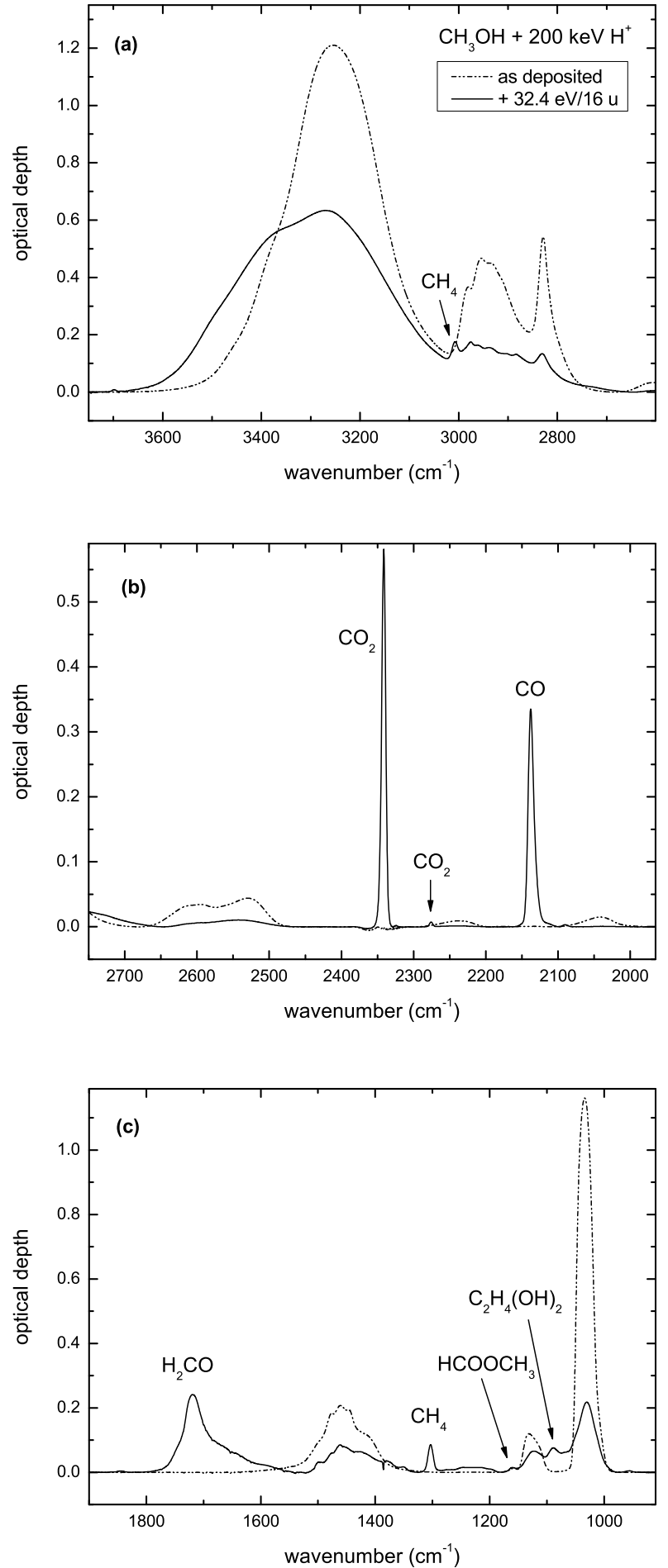

Fig. 8. Infrared spectra of a $\mathrm{CH}_{3} \mathrm{OH}$ pure ice as deposited (dotted lines) and after irradiation with $200 \mathrm{keV}$ protons (solid lines) in three different spectral regions from 3700 to $900 \mathrm{~cm}^{-1}(2.70-11.11 \mu \mathrm{m})$.

see the new band centered at $3700 \mathrm{~cm}^{-1}$ due to $\mathrm{CO}_{2}$ and the band at $3010 \mathrm{~cm}^{-1}$ due to $\mathrm{CH}_{4}$. In panel (b) the bands of ${ }^{12} \mathrm{CO}$ and ${ }^{12} \mathrm{CO}_{2}$ are out of scale. The new band at $2280 \mathrm{~cm}^{-1}$ is due to ${ }^{13} \mathrm{CO}_{2}$, the band at $2089 \mathrm{~cm}^{-1}$ is due to ${ }^{13} \mathrm{CO}$. In panel (c) there is the new band at $1843 \mathrm{~cm}^{-1}$ due to $\mathrm{HCO}$, the band at $1720 \mathrm{~cm}^{-1}$ due to $\mathrm{H}_{2} \mathrm{CO}$, and the band at $1304 \mathrm{~cm}^{-1}$ due to $\mathrm{CH}_{4}$. In panel (d) there is the band at $660 \mathrm{~cm}^{-1}$ due to $\mathrm{CO}_{2}$ and the band at $1090 \mathrm{~cm}^{-1}$ due to HCO. The inset in panel (d) shows the spectral region between 1180 and $980 \mathrm{~cm}^{-1}$ after irradiation at
Table 3. Position, assignment and characterization of new bands observed after irradiation of $\mathrm{CO}: \mathrm{CH}_{3} \mathrm{OH}$ mixture at $16 \mathrm{~K}$.

\begin{tabular}{|c|c|c|c|c|}
\hline \multicolumn{2}{|c|}{ Band position } & Species & Assignment & Characterization \\
\hline 660 & 15.15 & $\overline{\mathrm{CO}_{2}}$ & $v_{2}$ & bend \\
\hline 1067 & 9.37 & $\mathrm{HCOCH}_{2} \mathrm{OH}$ & $v_{7}$ & $\mathrm{C}-\mathrm{O}$ str \\
\hline 1090 & 9.17 & $\mathrm{HCO}$ & $v_{2}$ & bend \\
\hline 1159 & 8.63 & $\mathrm{HCOOCH}_{3}$ & $v_{9}$ & $\mathrm{CH}_{2}$ rock \\
\hline 1247 & 8.02 & $\mathrm{H}_{2} \mathrm{CO}$ & $v_{2}$ & $\mathrm{CH}_{2}$ rock \\
\hline 1304 & 7.66 & $\mathrm{CH}_{4}$ & $v_{4}$ & deform \\
\hline 1500 & 6.67 & $\mathrm{H}_{2} \mathrm{CO}$ & $v_{3}$ & $\mathrm{CH}_{2}$ scis \\
\hline 1726 & 5.79 & $\mathrm{H}_{2} \mathrm{CO}$ & $v_{2}$ & $\mathrm{C}=\mathrm{O}$ str \\
\hline 1843 & 5.43 & $\mathrm{HCO}$ & $v_{3}$ & $\mathrm{C}=\mathrm{O}$ str \\
\hline 2280 & 4.39 & ${ }^{13} \mathrm{CO}_{2}$ & $v_{3}$ & $\mathrm{C}=\mathrm{O}$ str \\
\hline 2325 & 4.30 & $\mathrm{OC}^{18} \mathrm{O}$ & $v_{3}$ & $\mathrm{C}=\mathrm{O}$ str \\
\hline 2342 & 4.27 & $\mathrm{CO}_{2}$ & $v_{3}$ & $\mathrm{C}=\mathrm{O}$ str \\
\hline 3010 & 3.32 & $\mathrm{CH}_{4}$ & $v_{3}$ & C-H str \\
\hline 3700 & 2.70 & $\mathrm{CO}_{2}$ & & combination \\
\hline
\end{tabular}

$5.2 \mathrm{eV} / 16 \mathrm{u}$. In this region two weak bands due to $\mathrm{C}_{2} \mathrm{H}_{4} \mathrm{O}_{2}$ isomers are visible: the band at $1067 \mathrm{~cm}^{-1}$ due to glycolaldehyde $\left(\mathrm{HCOCH}_{2} \mathrm{OH}\right)$ and the band at about $1160 \mathrm{~cm}^{-1}$ that we attribute to methyl formate $\left(\mathrm{HCOOCH}_{3}\right)$. The position of this band is in accordance with a methyl formate band (see Fig. 2) due to the rocking of $\mathrm{CH}_{3}$ ( $v_{9}$ fundamental mode).

In the spectra of the $\mathrm{CO}: \mathrm{CH}_{3} \mathrm{OH}$ mixture three methanol bands are present, at $2830 \mathrm{~cm}^{-1}\left(\mathrm{CH}_{3}\right.$ stretching $)$, at $1128 \mathrm{~cm}^{-1}$ $\left(\mathrm{CH}_{3}\right.$ rocking), at $1033 \mathrm{~cm}^{-1}$ (C-O stretching), which are not superimposed to the bands of other species. We measured their band areas in the spectra after deposition and during irradiation. Figure 10 shows the data obtained as a function of dose after normalization to the initial value. The data show that after irradiation methanol is efficiently destroyed. The same trend is observed after irradiation of pure methanol.

\section{6. $1160 \mathrm{~cm}^{-1}$ band area}

A band at about $1160 \mathrm{~cm}^{-1}$ is present in the spectra of pure $\mathrm{CH}_{3} \mathrm{OH}$ and $\mathrm{CO}: \mathrm{CH}_{3} \mathrm{OH}$ mixture after ion irradiation. This band is a key element that proves the formation of methyl formate in the solid phase after irradiation. We measured the area of the band in the spectra of the mixture and plotted the obtained values as a function of irradiation dose. Data are shown in Fig. 11 by the open squares. This band overlaps another weak band, the methanol fundamental mode $v_{11}$ (visible in the enlargement in Fig. 7). Therefore the total area of the $1160 \mathrm{~cm}^{-1}$ band $\left(1160 a_{T}\right)$ receives the contribution by two molecular species: methanol $(M)$, already present in the sample as deposited, and methyl formate $(M F)$, formed after ion irradiation. Because we are interested in the study of the $\mathrm{HCOOCH}_{3}$ band, we need to remove the contribution by methanol to the total band area before and after irradiation. Here we describe this procedure. The following relation is valid:

$1160 a_{T}=1160 a_{M}+1160 a_{M F}$.

The $1160 \mathrm{~cm}^{-1}$ band area in the spectrum before irradiation receives only the contribution by methanol, so for the initial value $(i)$ we have

$1160 a_{T i}=1160 a_{M i}$.

The band at $1033 \mathrm{~cm}^{-1}$ is an isolated methanol band that we can use as representative of the methanol behavior in the spectra 
P. Modica and M. E. Palumbo: Formation of methyl formate
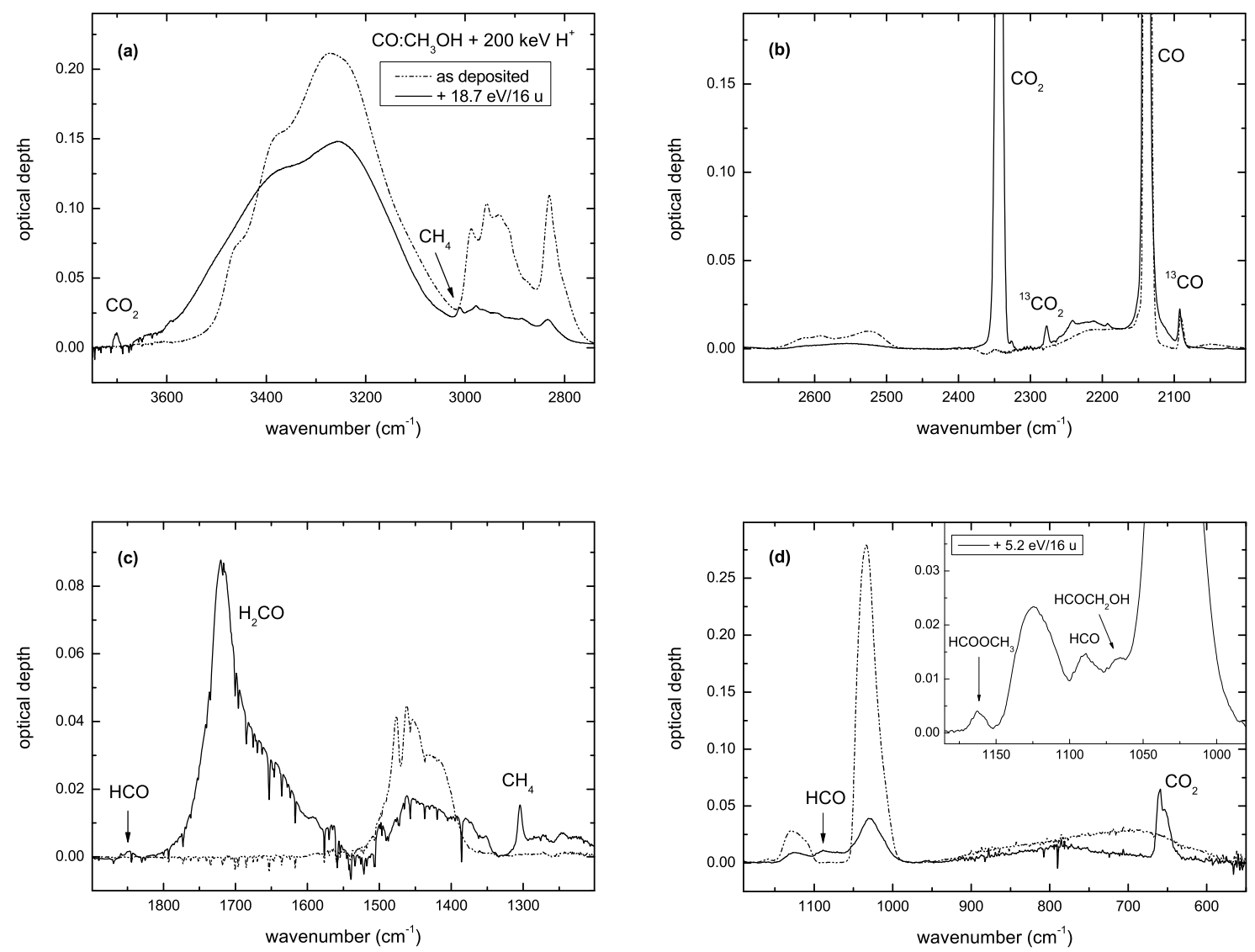

Fig. 9. Infrared spectra of the $\mathrm{CO}: \mathrm{CH}_{3} \mathrm{OH}$ ice before irradiation (dotted lines) and after irradiation with $200 \mathrm{keV}$ protons (solid lines) in four different spectral regions from 3800 to $550 \mathrm{~cm}^{-1}(2.63-18.18 \mu \mathrm{m})$. The inset of panel d) shows the spectral region $1180-980 \mathrm{~cm}^{-1}$ after a dose of $5.2 \mathrm{eV} / 16 \mathrm{u}$.

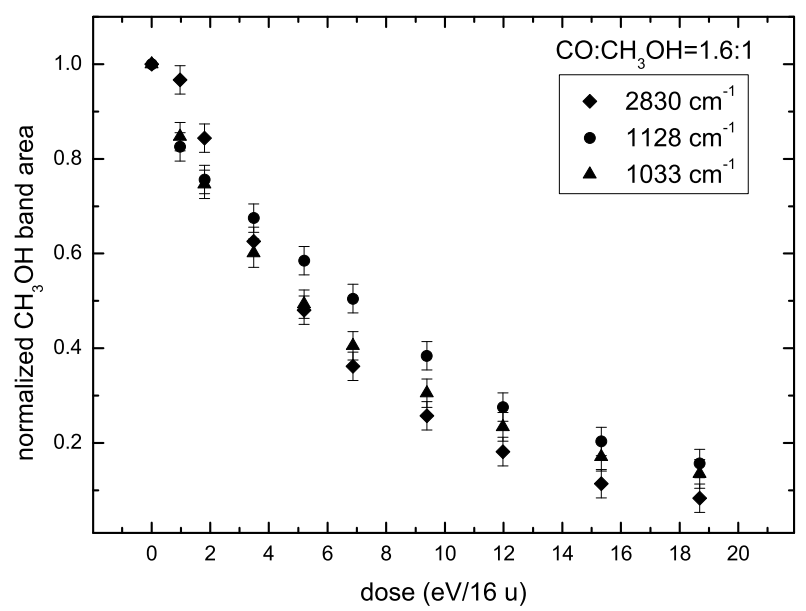

Fig. 10. Plot of the band area, normalized to the first value, versus dose for three methanol bands.

of the mixture (see Sect. 3.5 and Fig. 10). We calculated the ratio $(R)$ between $1160 \mathrm{~cm}^{-1}$ and $1033 \mathrm{~cm}^{-1}$ band areas in the spectrum before irradiation:

$$
\frac{1160 a_{M i}}{1033 a_{M i}}=R
$$

Before irradiation the value of $R$ is 0.0016 . Assuming that $R$ is maintained constant also after irradiation, we can evaluate the

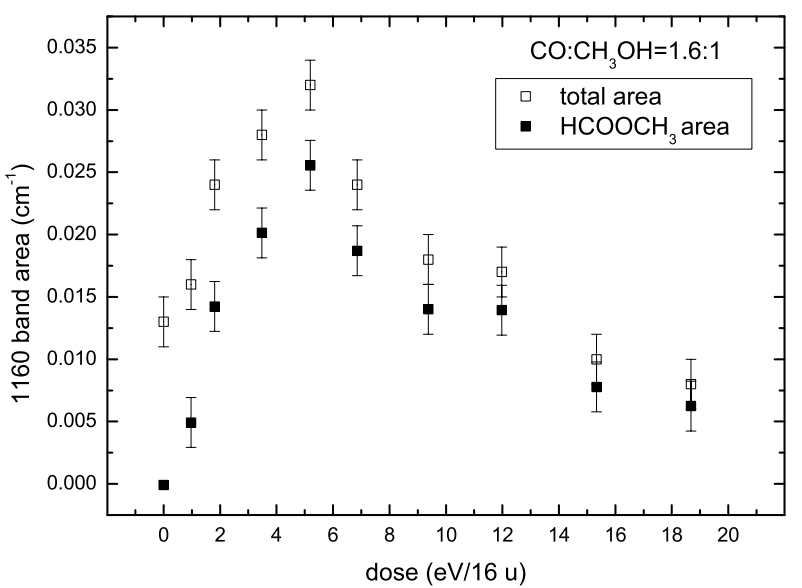

Fig. 11. $1160 \mathrm{~cm}^{-1}$ band area versus dose. Open squares refer to the total area, filled squares refer to the area due to methyl formate.

contribution by methanol to the $1160 \mathrm{~cm}^{-1}$ band area at different doses:

$1160 a_{M}=R \times 1033 a_{M}$.

By substituting this value in Eq. (6) we can easily subtract the contribution by methanol to the $1160 \mathrm{~cm}^{-1}$ total band area in each spectrum. After the subtraction we obtained the area values due to methyl formate (filled squares in Fig. 11). The data show a two-step pattern: in the first step the trend is growing up, in the second step it is slowly descending. Because in optical depth 


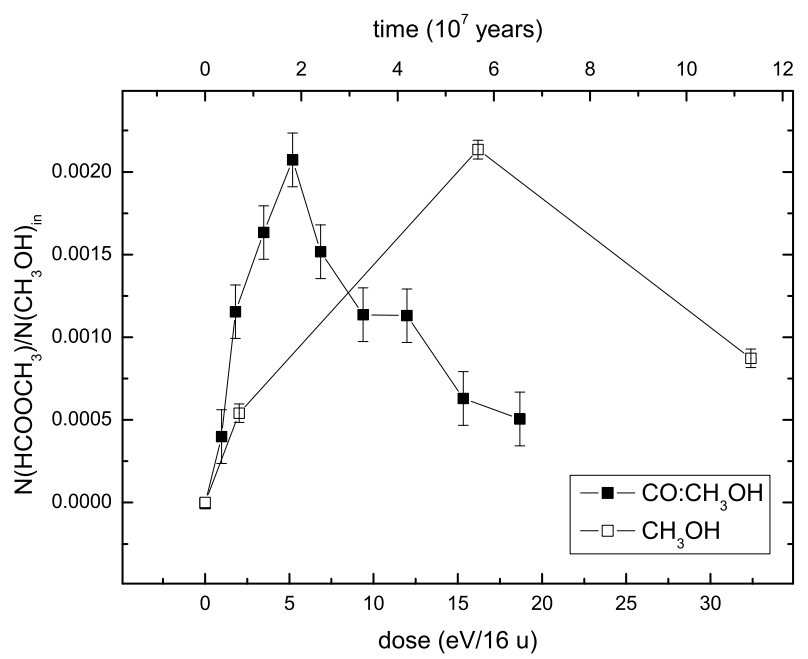

Fig. 12. Methyl formate column density ratioed to methanol initial column density versus time (top $x$-axis) and different suffered doses (bottom $x$-axis) in the mixture (filled squares) and in pure methanol (open squares). Solid lines have been drawn only to guide the eye.

scale the intensity of a not saturated band increases linearly with the amount of the responsible molecules present in the sample, we interpreted this trend as indicating the formation of methyl formate in the first step and its gradual destruction in the second step. Our previous experiments (see Sects. 2.2 and 3.2) enabled us to obtain an estimate of the amount of methyl formate present in the mixture after irradiation. The column density of methyl formate was easily monitored using the equation

$N=\frac{\int \tau(v) \mathrm{d} v}{A}$,

where $A=1.96 \times 10^{-17} \mathrm{~cm} \mathrm{molecule}-1$ is the $1164 \mathrm{~cm}^{-1}$ band strength value given in Table 2 . We chose to express the abundance of methyl formate with respect to methanol initial abundance. The column density of methanol has been estimated from the $1033 \mathrm{~cm}^{-1}$ band using $A=1.3 \times 10^{-17} \mathrm{~cm} \mathrm{molecule}^{-1}$ (Palumbo et al. 1999). Figure 12 shows the estimated $N\left(\mathrm{HCOOCH}_{3}\right) / N\left(\mathrm{CH}_{3} \mathrm{OH}\right)$ ratio relative to initial methanol as a function of the dose. We show a comparison between the mixture and the pure methanol samples. For the mixture, the ratio reaches the order of $10^{-3}$ at low doses (about $2 \mathrm{eV} / 16 \mathrm{u}$ ).

\section{Discussion}

We performed several laboratory experiments. In particular we analyzed a sample of frozen pure methanol $\left(\mathrm{CH}_{3} \mathrm{OH}\right)$ and a mixture of methanol and carbon monoxide $\left(\mathrm{CO}: \mathrm{CH}_{3} \mathrm{OH}=1.6: 1\right)$. Maintaining a constant temperature $(16 \mathrm{~K})$, both samples were irradiated with $200 \mathrm{keV}$ protons and analyzed by infrared spectroscopy before, during, and after irradiation. The results of the experiments showed that in both samples the irradiation can induce the formation of methyl formate, which has been identified through the band at about $1160 \mathrm{~cm}^{-1}$.

In Fig. 13 we overlaid the spectrum of the mixture after a dose of $5.2 \mathrm{eV} / 16 \mathrm{u}$ and the spectrum of methyl formate as deposited, zooming in for clarity the region between 1800 and $950 \mathrm{~cm}^{-1}$ where the three most intense bands of methyl formate are. We did not show the spectral region beyond $950 \mathrm{~cm}^{-1}$ because unfortunately the spectra are too noisy, so it is not possible to quantitatively analyze the bands at $910 \mathrm{~cm}^{-1}$ and at $768 \mathrm{~cm}^{-1}$

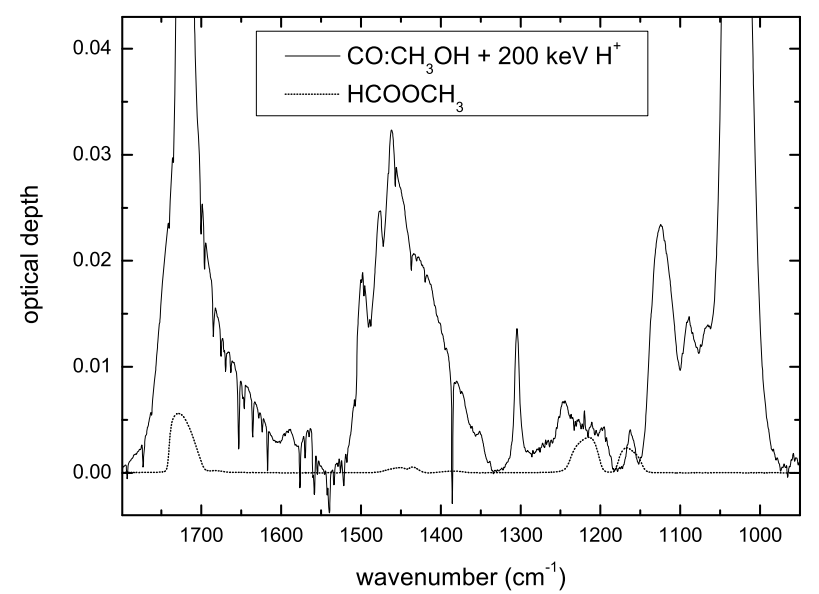

Fig. 13. Contribution of methyl formate to the intensity of the bands in the irradiated $\mathrm{CO}: \mathrm{CH}_{3} \mathrm{OH}$ mixture.

of methyl formate. Considering that methyl formate contributes with about $80 \%$ to the $1160 \mathrm{~cm}^{-1}$ band area in the spectrum, we appropriately reduced the y-scale of the $\mathrm{HCOOCH}_{3}$ spectrum until this condition was realized and until its other bands fell within the corresponding bands in the spectrum of the mixture. As we can see, the spectrum of methyl formate is compatible with the spectrum of the irradiated mixture, indeed the three bands of $\mathrm{HCOOCH}_{3}$ are perfectly centered at the position of the bands present in the spectrum of the irradiated mixture. The band at $1160 \mathrm{~cm}^{-1}$ in the spectrum of $\mathrm{HCOOCH}_{3}$ presents a FWHM greater than that in the spectrum of the irradiated $\mathrm{CO}: \mathrm{CH}_{3} \mathrm{OH}$ mixture. As discussed in Sect. 3.4 for the $\mathrm{CH}_{3} \mathrm{OH}: \mathrm{HCOOCH}_{3}$ mixture, this evidence can be considered as a natural behavior of the band when methyl formate is mixed with other species.

Despite the non-rigorous method used, but in agreement with our previous results, we managed to find the hypothetical contribution to the band intensity of the irradiated mixture due to methyl formate. Unfortunately we could not find bands solely attributable to methyl formate because the abundance of the molecules in the sample is small and the strongest bands of the molecule are shared with those of other species. In particular, the broad feature around $1230 \mathrm{~cm}^{-1}$ present after irradiation of the mixture could be due to the contribution by $\mathrm{H}_{2} \mathrm{CO}$ (formaldehyde), $\mathrm{HCOOH}$ (formic acid), $\mathrm{CH}_{3} \mathrm{COCH}_{3}$ (acetone), and $\mathrm{CH}_{2} \mathrm{OH}$ (methoxy radical) (Öberg et al. 2009; Bennett et al. 2007; Hudson \& Moore 2000; Palumbo et al. 1999; Gerakines et al. 1996).

As shown in Fig. 12, for both samples the amount of methyl formate, which is progressively produced by irradiation, is on the order of $10^{-3}$ with respect to the amount of methanol initially present in the samples as deposited. These results, applied to the astrophysical analysis, suggest that during continuous exposure of the icy mantles to low-energy cosmic rays, one part out of $10^{3}$ of initial methanol could be converted into methyl formate, while the part that does not participate in the formation of this molecule should be gradually destroyed, forming other molecular species, the most abundant of which are $\mathrm{CO}$, $\mathrm{CO}_{2}, \mathrm{CH}_{4}, \mathrm{H}_{2} \mathrm{CO}$ (Palumbo et al. 1999; Hudson \& Moore 2000; Baratta et al. 2002).

In order to estimate the time necessary to obtain the effects observed in the laboratory in dense molecular clouds we consider the approximation of effective monoenergetic $1 \mathrm{MeV}$ protons and assume that in dense interstellar regions 

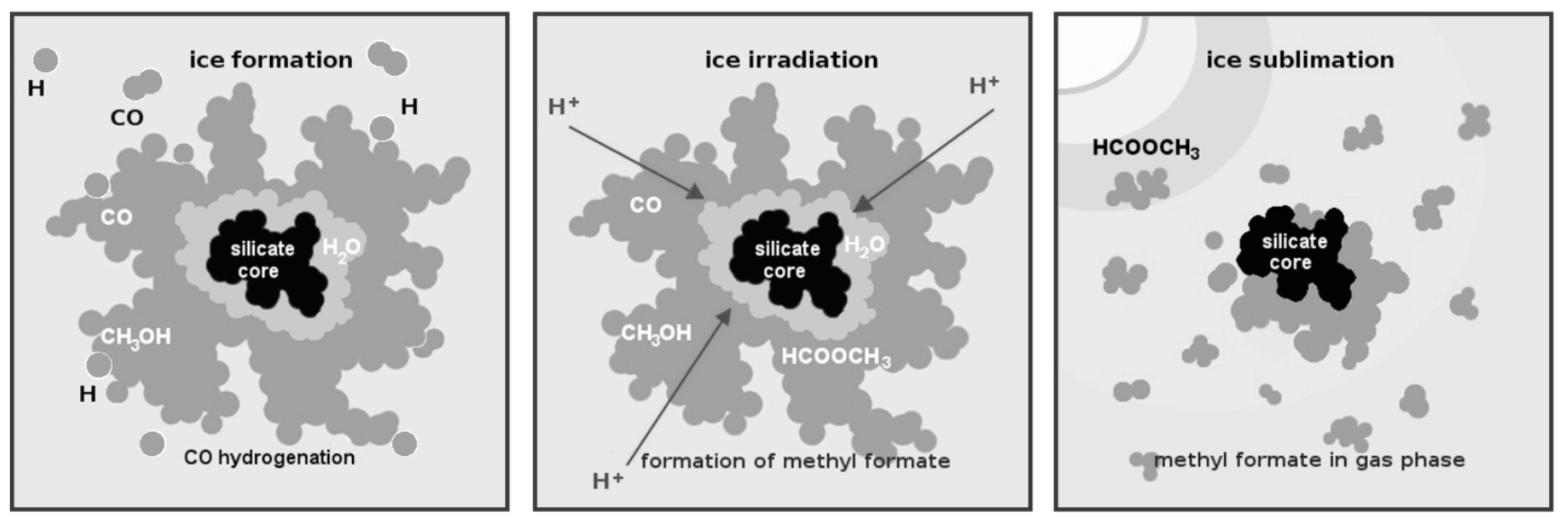

Fig. 14. Formation of methyl formate on icy grain mantles and release to the gas-phase. Left panel: $\mathrm{CO}$ hydrogenation and formation of $\mathrm{CH}_{3} \mathrm{OH}$. Middle panel: interaction with cosmic rays and formation of $\mathrm{HCOOCH}_{3}$. Right panel: rise of temperature and $\mathrm{HCOOCH}_{3}$ sublimation.

the $1 \mathrm{MeV}$ flux is equal to 1 proton $\mathrm{cm}^{-2} \mathrm{~s}^{-1}$ (Mennella et al. 2003). Our experimental results were obtained using $200 \mathrm{keV}$ protons. Thus in order to extrapolate the laboratory results to the interstellar medium conditions we assume that they scale with the stopping power ( $\mathrm{S}$, energy loss per unit path length) of impinging ions. With these hypotheses we indicated in Fig. 12 the timescale axis (top $x$-axis), which gives an estimation of the time $\left(10^{7}\right.$ years) necessary to obtain the effects observed in the laboratory on interstellar ices. We obtained that about $2 \times 10^{7}$ years would be necessary to form the observed column density of methyl formate. This time agrees with the evolutionary timescale $\left(3 \times 10^{7}-5 \times 10^{8}\right.$ years $)$ of molecular clouds (Greenberg 1982). Methyl formate has also been observed in Class 0 objects (e.g. Bottinelli et al. 2004a,b, 2007). It has been estimated that these objects have a dynamical age of a few thousand years (e.g. Maret et al. 2002; Bottinelli et al. 2004a,b). According to current models, low-mass stars form inside molecular clouds from dense and cold condensations, called prestellar cores, which evolve into Class 0 and then Class I sources. Prestellar cores are characterized by low temperature $(T \leq 10 \mathrm{~K})$ and high density $\left(n \geq 10^{6} \mathrm{~cm}^{-3}\right)$. High depletion of gas phase species has been observed towards prestellar cores (e.g. Tafalla et al. 2004, 2006), suggesting that ice grain mantles are present in these regions. Furthermore ice grain mantles have been observed in quiescent regions of dense molecular clouds (e.g. Chiar et al. 1994, 1995; Whittet et al. 1998; Knez et al. 2005). These results suggest that ice mantles could be as old as the molecular cloud in which they are detected and then suffer from cosmic ion irradiation for a time as long as the molecular cloud's lifetime (e.g. Palumbo \& Strazzulla 1993).

Observations have shown that in hot cores and hot corinos the fractional abundance of methyl formate can vary in a wide range of magnitudes, but generally it is on the order of $10^{-7}-10^{-9}$ with respect to $\mathrm{H}_{2}$. The laboratory experiments presented here indicate that after ion irradiation of $\mathrm{CO}: \mathrm{CH}_{3} \mathrm{OH}$ ice at $16 \mathrm{~K}$ the amount of methyl formate is on the order of $10^{-3}$ with respect to initial methanol. In order to compare our results with the observational data we need to express this value with respect to $\mathrm{H}_{2}$. In dense molecular clouds the fractional abundance of $\mathrm{CO}$ is on the order of $10^{-4}$ with respect to $\mathrm{H}_{2}$ (Frerking et al. 1982). Experimental results revealed that $\mathrm{CH}_{3} \mathrm{OH}$ can be produced efficiently by successive hydrogenation of $\mathrm{CO}$ on grain surfaces at temperatures that are typical in molecular clouds (Watanabe et al. 2007; Fuchs et al. 2009), and the amount of $\mathrm{CH}_{3} \mathrm{OH}$ obtained is at least on the order of $10^{-1}$ with respect to CO. Other authors suggest that this amount could be higher (Fuchs et al. 2009). Thus if we assume high $\mathrm{CO}$ depletion we can say that the fractional abundance of solid $\mathrm{CH}_{3} \mathrm{OH}$ is on the order of $10^{-5}$ with respect to $\mathrm{H}_{2}$. Moreover, if we assume that methyl formate/methanol column density ratio obtained in the solid state after ion irradiation is maintained in the gas phase after desorption of icy grain mantles, we obtain an amount of methyl formate on the order of $10^{-8}$ with respect to $\mathrm{H}_{2}$. This amount is consistent with the observed abundances. For example, the fractional abundance of methyl formate in Sgr B2 $\mathrm{N}(\mathrm{LMH})$ is $1.1 \times 10^{-8}$ (Snyder 2006), in IRAS 16293-2422 B it is $>1.2 \times 10^{-8}$ (Remijan \& Hollis 2006), in NGC 2264 MMS it is $(0.7-5.3) \times 10^{-8}$ (Sakai et al. 2007).

In the light of our results we can propose the model illustrated in Fig. 14. Gas-phase processes produce a high abundance of carbon monoxide, some of which is deposited on the grain surface, where it is partially hydrogenated into formaldehyde and methanol. During their lifetime, icy grain mantles containing $\mathrm{CO}$ and $\mathrm{CH}_{3} \mathrm{OH}$ interact with low-energy cosmic rays. As a consequence of ion irradiation, methyl formate is produced within interstellar ices. Once this molecule is formed, it can subsequently be released into the gas phase after desorption mechanisms, i.e., when a young stellar object begins to form and the icy mantles sublime.

\section{Conclusion}

Methyl formate may have played a decisive role in the development of life on our planet. It is therefore crucial to understand what the process of formation of this molecule is in order to include it in the evolutionary models of molecular clouds and to explain the formation of planetary systems. Armed with correct model predictions, it will be possible to conduct meaningful searches of new complex organic molecules. It is likely that different formation processes contribute in different ways at different times of the protostar evolution. We suggested that interaction of icy grain mantles with low-energy cosmic rays could be considered a dominant mechanism in the formation of methyl formate. The analysis of laboratory data allow us to suggest that the gas phase methyl formate observed in the interstellar medium is formed in the solid state after cosmic ion irradiation of icy mantles containing $\mathrm{CO}$ and $\mathrm{CH}_{3} \mathrm{OH}$ and released to the gas phase after desorption of icy mantles.

Methyl formate has two isomers, glycolaldehyde and acetic acid. Differentiation in the molecular isomers has been observed, 
but not explained. Because the set of the three isomers share the same chemical formula $\left(\mathrm{C}_{2} \mathrm{H}_{4} \mathrm{O}_{2}\right)$, they could also share the same formation process. Our experiments have indeed revealed a weak band that could be attributed to glycolaldehyde. However, we need further and more detailed experimental works to confirm this suggestion. As future work we plan to study the formation of glycolaldehyde and acetic acid after ion irradiation of $\mathrm{CO}: \mathrm{CH}_{3} \mathrm{OH}$ ice mixtures. Major advances in understanding the formation chemistry of these molecules can come from observational projects like ALMA (Atacama Large Millimeter Array), EVLA (Expanded Very Large Array) and the Herschel satellite, all of which expect astrochemistry to be an important component of their scientific programs.

Acknowledgements. The authors wish to thank F. Spinella for his technical assistance in the laboratory, and G. A. Baratta and G. Strazzulla for fruitful discussions during the preparation of this work. This research has been financially supported by the Italian Space Agency contract No. I/015/07/0 (Studi di Esplorazione del Sistema Solare).

\section{References}

Baratta, G. A., \& Palumbo, M. E. 1998, J. Opt. Soc. Am. A, 15, 3076

Baratta, G. A., Leto, G., \& Palumbo, M. E. 2002, A\&A, 384, 343

Bennett, C. J., \& Kaiser, R. I. 2007, ApJ, 661, 899

Bennett, C. J., Chen, S. H., Sun, B. J., Chang, A. H. H., \& Kaiser, R. I. 2007, ApJ, 660, 1588

Bockelée-Morvan, D., Lis, D. C., Wink, J. E., et al. 2000, A\&A, 353, 1101

Boogert, A. C. A., Pontoppidan, K. M., Knez, C., et al. 2008, ApJ, 678, 985

Bottinelli, S., Ceccarelli, C., Lefloch, B., et al. 2004a, ApJ, 615, 354

Bottinelli, S., Ceccarelli, C., Neri, R., et al. 2004b, ApJ, 617, 69

Bottinelli, S., Ceccarelli, C., Williams, J. P., et al. 2007, ApJ, 463, 601

Brown, R. D., Crofts, J. G., Gardner, F. F., et al. 1975, ApJ, 197, L29

Cazaux, S., Tielens, A. G. G. M., Ceccarelli, C., et al. 2003, ApJ, 593, 51

Chiar, J. E., Adamson, A. J., Kerr, T. H., \& Whittet, D. C. B. 1994, ApJ, 426, 240

Chiar, J. E., Adamson, A. J., Kerr, T. H., \& Whittet, D. C. B. 1995, ApJ, 455, 234
Despois, D., Biver, N., Bockelée-Morvan, D., \& Crovisier, J. 2005, in Astrochemistry: Recent Successes and Current Challenges, ed. D. C. Lis, G. A. Blake, \& E. Herbst (Cambridge University Press), IAU Symp., 231, 469

Frerking, M. A., Langer, W. D., \& Wilson, R. W. 1982, ApJ, 262, 590

Fuchs, G. W., Cuppen, H. M., Ioppolo, S., et al. 2009, A\&A, 505, 629

Fulvio, D., Sivaraman, B., Baratta, G. A., et al. 2009, Spectrochim. Acta A, 72, 1007

Gerakines, P. A., Schutte, W. A., \& Ehrenfreund, P. 1996, A\&A, 312, 289

Gerakines, P. A., Whittet, D. C. B., Ehrenfreund, P., et al. 1999, ApJ, 522, 357

Greenberg, J. M. 1982, in Comets, ed. L. L. Wilkening (Tucson: The University of Arizona Press), 131

Grim, R. J. A., \& Greenberg, J. M. 1987, ApJ, 321, L91

Horn, A., Mollendal, H., Sekiguchi, O., et al. 2004, ApJ, 611, 605

Hudson, R. L., \& Moore, M. H. 2000, Icarus, 145, 661

Knez, C., Boogert, A. C. A., Pontoppidan, K. M., et al. 2005, ApJ, 635, L145

Kuan, Y. J., Huang, H. C., Charnley, S. B., et al. 2004, ApJ, 616, 27

Ikeda, M., Ohishi, M., Nummelin, A., et al. 2001, ApJ, 560, 792

Maret, S., Ceccarelli, C., Caux, E., Tielens, A. G. G. M., \& Castets, A. 2002, A\&A, 395, 573

Mennella, V., Baratta, G. A., Esposito, A., Ferini, G., \& Pendleton, Y. J. 2003, ApJ, 587, 727

Öberg, K. I., van Dishoeck, E. F., \& Linnartz, H. 2009, A\&A, 504, 891

Palumbo, M. E., \& Strazzulla, G. 1993, A\&A, 269, 568

Palumbo, M. E., Castorina, A. C., \& Strazzulla, G. 1999, A\&A, 342, 551

Palumbo, M. E., Ferini, G., \& Baratta, G. A. 2004, Adv. Sp. Res., 33, 49

Remijan, A. J., \& Hollis, H. 2006, ApJ, 640, 842

Remijan, A. J., Friedel, D. N., de Pater, I., et al. 2006, ApJ, 643, 567

Sakai, N., Sakai, T., \& Yamamoto, S. 2007, ApJ, 660, 363

Sandford, S. A., \& Allamandola, L. J. 1993, ApJ, 417, 815

Sandford, S. A., Aleon, J., Alexander, C. M. O. D., et al. 2006, Science, 314, 1720

Snyder, L. E. 2006, Proc. Natl. Sci., 103, 12243

Strazzulla, G., \& Johnson, R. E. 1991, in Comets in the post-Halley era, ASSL Series, Dordrecht, 1, 243

Strazzulla, G., Baratta, G. A., \& Palumbo, M. E. 2001, Spectrochem. Acta Part A, 57, 825

Tielens, A. G. G. M., \& Hagen, W. 1982, A\&A, 114, 245

Watanabe, N., Mouri, O., Nagaoka, T., et al. 2007, ApJ, 668, 1001

Whittet, D. C. B., Gerakines, P. A., Tielens, A. G. G. M., et al. 1998, ApJ, 498, L159 